\title{
Use of E-Learning in the Process of Knowledge Sharing in IAIN Kendari, Southeast Sulawesi, Indonesia
}

\author{
Ambar Sri Lestari \\ Institute of Islamic Religious (IAIN), Kendari, Indonesia
}

\begin{abstract}
This study aims to find out how the process of knowledge sharing as a means of delivering information and knowledge submitted to other people in learning. The process of learning lasts by using synchronous (face-to-face) and asynchronous (e-learning) methods. There are four activities in e-learning, namely: (a) individualized self-paced e-learning online; (b) individualized self-paced e-learning offline; (c) group-based e-learning synchronously; and (d) group-based e-learning asynchronously. In this study, the Constructivist Online Learning Environment Survey (COLLES) was used, namely, a questionnaire that specifically aimed to know the use of the online learning system (e-learning) by teachers and students in supporting the process of knowledge sharing. COLLES covers six things: relevance, reflection, interaction, tutor support, peer support, and making sense. Overall, the students conducting knowledge sharing have a high degree of relevance of $3.98 \%$ on materials provided, then amounting $3.96 \%$ on reflection, tutor support, peer support, and making sense, and the interaction aspects amounting 3.95\%. It shows that the students are still feel comfortable with synchronous learning. However, asynchronous learning through e-learning needs to be improved by existing discussion forums, emails, chats, blogs, and SlideShare.
\end{abstract}

Keywords: synchronous, asynchronous, e-learning, knowledge sharing, Constructivist Online Learning Environment Survey (COLLES)

\section{Introduction}

Learning, now, is facing two challenges. The first challenge comes from the change in perception about learning itself and the second challenge comes from the existence of information and communications technology (ICT) that shows a remarkable development. Constructivism has basically addressed the first challenge by redefining learning as a constructive process where information is converted to knowledge through the process of interpretation, correspondence, representation, and elaboration. Meantime, the rapid advances in ICT offer a wide range ease of learning that allows the change of orientation from outside-guided learning to self-guided and from knowledge-as-possession to knowledge-as-construction. More than that, ICT also plays an important role in renewing the original conception of learning from learning as solely a presentation of various knowledge to learning as guidance to explore the social culture in knowledge. Utilization of ICT in learning continues to evolve today. Learning materials are an important element in the utilization of ICT for learning. To this end, a teacher's ability in developing Web-based learning materials becomes important. Teaching materials are any forms of content text, audio, photos, video, animation, and

Ambar Sri Lestari, Doctor of Management Education, lecturer, Faculty of Teacher Training and Education, IAIN. 
others, which can be used to learn. The main purpose of this study of knowledge sharing is to use information technology as a form of learning medium and to improve the effectiveness and efficiency of the learning process. This study contributes to deeper understanding relating to knowledge sharing. Web-based learning system begins with the development of the Internet, and then creates opportunities and challenges for all teachers at all levels.

This study is guided by the following six research questions:

1. How is the relevance (suitability) between the e-learning system and the user's knowledge level? (Relevance)

2. Whether the e-learning system stimulates students to think critically and openly? (Reflection)

3. Can students participate in the process of knowledge sharing through e-learning? (Interactivity)

4. How is the tutor support among fellow students in the e-learning system? (Tutor support)

5. How is the peer support among fellow students in the e-learning system? (Peer support)

6. Whether students and teachers have a common understanding in communicating online? (Interpretation)

\section{Literature Review}

Nichols (2001) (as cited in Rosenberg, 2001, p. 44) defined e-learning as a "pedagogy empowered by digital technology", which means that e-learning can be defined in brief as learning that is fully supported by digital technology. According to Soekartawi, Haryono, and Librero (2002):

E-learning is a generic term for all technologically supported learning using an array of teaching and learning tools as phone bridging, audio and videotapes, teleconferencing, satellite transmissions, and the more recognized Web-based training or computer-aided instruction also commonly referred to as online courses. (p. 56)

The definition of e-learning has several elements of what, how, and why, as said by Clark and Mayer (2008):

1. What. E-learning includes both content, i.e., the information, and instructional methods, that is technique, which helps people to learn of learning content;

2. How. E-learning is distributed through a computer in the form of sentences and images. Distribution can be in the form of asynchronous which is designed to learn individually and in synchronous which is designed with the guidance of the instructor directly;

3. Why. E-learning is intended to help students achieve learning goals or perform the work. (p. 10)

E-learning is a form of learning that uses the electronic media as a supporter of the teaching and learning process, which combines all learning activities, whether individual or group, directly or indirectly. "E-learning would incorporate all educational activities that are carried out by individuals or groups working online or offline, and synchronously or asynchronously via networked or standalone computers and other electronic devices" (Naidu, 2006, p. 1). Electronic media meant here are computerized technology-based media. The following are some forms of e-learning activities performed (see Figure 1) (Naidu, 2006):

1. Individualized self-paced e-learning online: It is an situation in which an individual learns with accessing the source material (content resources) through intranet and Internet. A typical form of this activity is that a student conducts the process of learning through the Internet or using the Internet as a source material (resources);

2. Individualized self-paced e-learning offline: It is a situation in which an individual learns with accessing the database from learning materials offline (not connected to the intranet or Internet media). A typical form of 
this activity is learning by using materials that have been stored on the hard disk or compact disk;

3. Group-based e-learning synchronously: It leads to a situation in which a group of students cooperate in the process of learning through intranet and Internet media. In this type of activity, text-based conferencing and communications using audio and video conferencing are included;

4. Group-based e-learning asynchronously: It leads to a situation in which the students perform communication and collaborative learning processes in real-time or the delay (time-delay). One typical example of the activity in the learning process is to use a mailing list as a tool to communicate and collaborate.

\begin{tabular}{|c|c|}
\hline $\begin{array}{c}\text { Individualized self-paced } \\
\text { e-learning online }\end{array}$ & $\begin{array}{c}\text { Individualized self-paced } \\
\text { e-learning offline }\end{array}$ \\
\hline $\begin{array}{c}\text { Group-based } \\
\text { e-learning synchronously }\end{array}$ & $\begin{array}{c}\text { Group-based } \\
\text { e-learning asynchronously }\end{array}$ \\
\hline
\end{tabular}

Figure 1. E-learning modalities (Naidu, 2006, pp. 1-2).

According to Effendi and Zhuang (2005, p. 15), the advantages of e-learning include cost, time flexibility, place flexibility, teaching effectiveness, and availability of on-demand, while limitations of e-learning include culture, investment, technology, infrastructure, and materials.

Knowledge sharing is the exchange process of knowledge/information (skills, experience, and an understanding) between two or more people. Knowledge sharing is an activity to help people work together, facilitate the exchange of their knowledge, improve organization learning, and improve the ability to achieve individual goals and objectives of the organization. With the functions provided in e-learning, the stages of developing knowledge sharing in e-learning have been built, namely:

1. Knowledge: Knowledge provides the ability to respond to new situations. Knowledge is the result of a learning process that must be managed effectively to ensure the basic objectives can be achieved. Knowledge can be presented explicitly (in the form of database information, policies, and procedures), or implicitly (tacit knowledge, organizational culture, customs, etc.). For each individual, knowledge can give birth to an idea, an opinion, a talent, a relationship, a perspective, or a concept. While joint knowledge can be transformed into the form of technology, products, services, customs, facilities, and systems. E-learning requires the knowledge acquired by a person, or a group of people, or community to be managed, so it can be used in a wider range;

2. Database: One form of knowledge representation is the use of a database. The database knowledge is the basic form of e-learning. By using the software, a user will be able to search using the index and guide with questions through the instructions to do an assignment;

3. Software: Software will be developed and analyzed to determine the programming language, as well as tools required;

4. Hardware for server to users: The objective is to obtain a minimum specification of the most appropriate hardware to support the use of e-learning that is generated. From the server side, it will provide the most optimal service capabilities (speed of access and security). From the user side, it will obtain information that will help users plan the provision of hardware to take advantage of the resulting system;

5. Procedures or rules are necessary: Procedures and rules are available and widely communicated, which will facilitate the operation and maintenance of the system, and facilitate communication with the manager or 
the relationship between or among users;

6. Human resources (qualifications and competences): Functionally, human resources related to e-learning are grouped based on the interests of the use of e-learning and authority. The groupings are: (a) ordinary users, i.e., users who use e-learning for the purpose of teaching or learning services. This user group interface requires the most efficient system services, most exciting, and most easy to use; and (b) business systems, namely, those appointed to manage e-learning to keep up-to-date and in accordance with needs. Business systems should have the authority and the necessary technical competence in order to carry out their duties;

7. Resources for operational costs and maintenance of the system: To ensure the sustainability of the system, there is a need to analyze the operational and maintenance costs, and then formulate the patterns to get the source of the cost. With users and the various needs that are personal and institutional, e-learning is expected to facilitate a variety of user needs for improving the quality of the teaching and learning process. For this purpose, it is necessary to create a conducive learning environment, namely, the availability of communication among various users with ease; coordination of the activities of the user; and collaboration between user groups on the creation, modification, and deployment of knowledge, human intelligence, and product results. To realize e-learning environments, specific functions related to communication (e-mail and discussion forums), coordination, collaboration (can share knowledge or the result of human intelligence, and working space), and control are needed. E-learning systems require support for many of the functions of information, including gaining and indexing, capturing and archiving, searching and accessing, creating and recording, combining, constructing and modifying, and searching.

\section{Methods}

This research was conducted with the approach of descriptive research method, namely, a study that aims to describe a situation or phenomenon that occurs at this time with using scientific procedure to answer the actual problem. Descriptive research is the research that aims to understand the phenomenon of what is experienced by research subjects in a holistic manner, and by way of description in the form of words and language in a specific context (Moleong, 2007, p. 6).

\section{Participants}

In this study, the participants of the research (Suharsimi, 2002, p. 36) are the students who take the course in the second semester of the academic year 2013-2014 in the program of Islamic Religious Education (PAI) Semester IV A, B, and D and the program of teaching (KI) of Semester VI with the amount of 90 students.

\section{Data Collection}

Data collection is how researchers obtain valid and reliable data (Bungin, 2003, p. 42) and an instrument questionnaire was used in this study to collect data. The questionnaire is the structure of question that the respondents answered the questions themselves (Sulistyo, 2006, p. 110). The name of the questionnaire used in the research is Constructivist Online Learning Environment Survey (COLLES) (Taylor \& Maor, 2000), which specifically aimed to determine the use of online learning system (e-learning) by teachers and students in supporting the process of knowledge sharing. COLLES consists of 24 questions, then it was divided into six categories, and each category will describe the quality from the use of e-learning system, namely, relevance, reflection, interactivity, tutor support, peer support, and interpretation. 


\section{Data Analysis}

Data analysis method used in this study is the a descriptive analysis of the percentage. This descriptive percentage processed by frequency is divided by the number of respondents multiplied by $100 \%$ (Sudjana, 2001 , p. 129).

\section{Findings}

This study specifically aimed to determine the use of social media as a tool for knowledge sharing or the student learning with e-learning. In field observations, the researcher observed that the students in Institute of Islamic Religious (IAIN) Kendari generally often use and take advantage of social media on the Internet, regardless of its use for knowledge sharing. The students utilize social media as a means of communication in their daily lives. As for social media the students most used, according to the questionnaire given to students, they are Facebook, Tweeter, Email, Google+, and Blog.

From the results of the questionnaire on the use social media, on average, the students are already using social media, from the five options, the use of Facebook in social media accounts for as much as $7.06 \%$ and the use of Email as much as $7.43 \%$, which suggest that many of the students already know ICT as a tool in knowledge sharing in everyday life for assignments and as a means of communication. From the questionnaire results described above, the bulk of the students are already using e-mail as a means of delivering information to work on assignments, besides, Facebook is also used as a means of communication. This means that the students already run this knowledge sharing through existing social media and use it as a tool in the learning process or in communication. However, the application and use of the blogs are still lacking, and this needs to be improved further by providing motivation and direction, so that the students have a great desire to utilize existing information technology media as a means of knowledge sharing, which in turn will create a culture of organization learning in academic life and will be expected to become a habit of daily life.

Overall, the students conducting knowledge sharing have a high degree of relevance of 3.98\% on materials provided, then amounting $3.96 \%$ on reflection, tutor support, peer support, and making sense, and the interaction aspects amounting 3.95\%. Based on the analysis of the questionnaire results for each category of questions, it can be explained that:

1. In synchronous learning (face-to-face) or asynchronous (e-learning), the students get a good relevance between the two methods of learning, which shows that students get a direct experience which will be useful for the survival of their future in terms of professional jobs. This is evidenced by the enthusiasm of the students in implementing theories in practice, such as with assignment of product and go into the field to doing observations in schools;

2. In synchronous learning (face-to-face) or asynchronous (e-learning), the students receive reflections, tutor support, peer support, and making sense in a cozy atmosphere, meaning that students can reflect on their knowledge from tacit knowledge to explicit knowledge conversion with the reflection through critical discussions. Then, the relationship between tutor support, peer support, and making good sense finally provides comfort and confidence in each individual learning;

3. In synchronous learning (face-to-face) or asynchronous (e-learning), through interaction in the learning process, in fact the students still feel comfortable with doing direct interaction during the class or outside the class, and the use of media is still underutilized optimally. The reason for this difficulty is due to the WiFi network which can help students access the Internet quickly. Problems were found to be lack of a culture of 
learning through information technology, especially network problems, finally make the students are reluctant and fast/easy desperate to perform learning with the Internet media. In reality, it shows that tutors, friends, and the environment should be mutually supportive and motivating, so that students will transform themselves to want to use and utilize information technology well, therefore, support from lecturers or teachers in encouraging knowledge sharing (tutor support, peer support, and making sense) is needed, and facilities need to be improved for education advancement.

\section{Discussion}

The process of knowledge sharing in e-learning is done with the following steps:

1. Students open the e-learning website at the URL address http://www.elearning-ambarsrilestari.web.id/. Then, they can login with their username, password, and student ID number (see Figure 2).

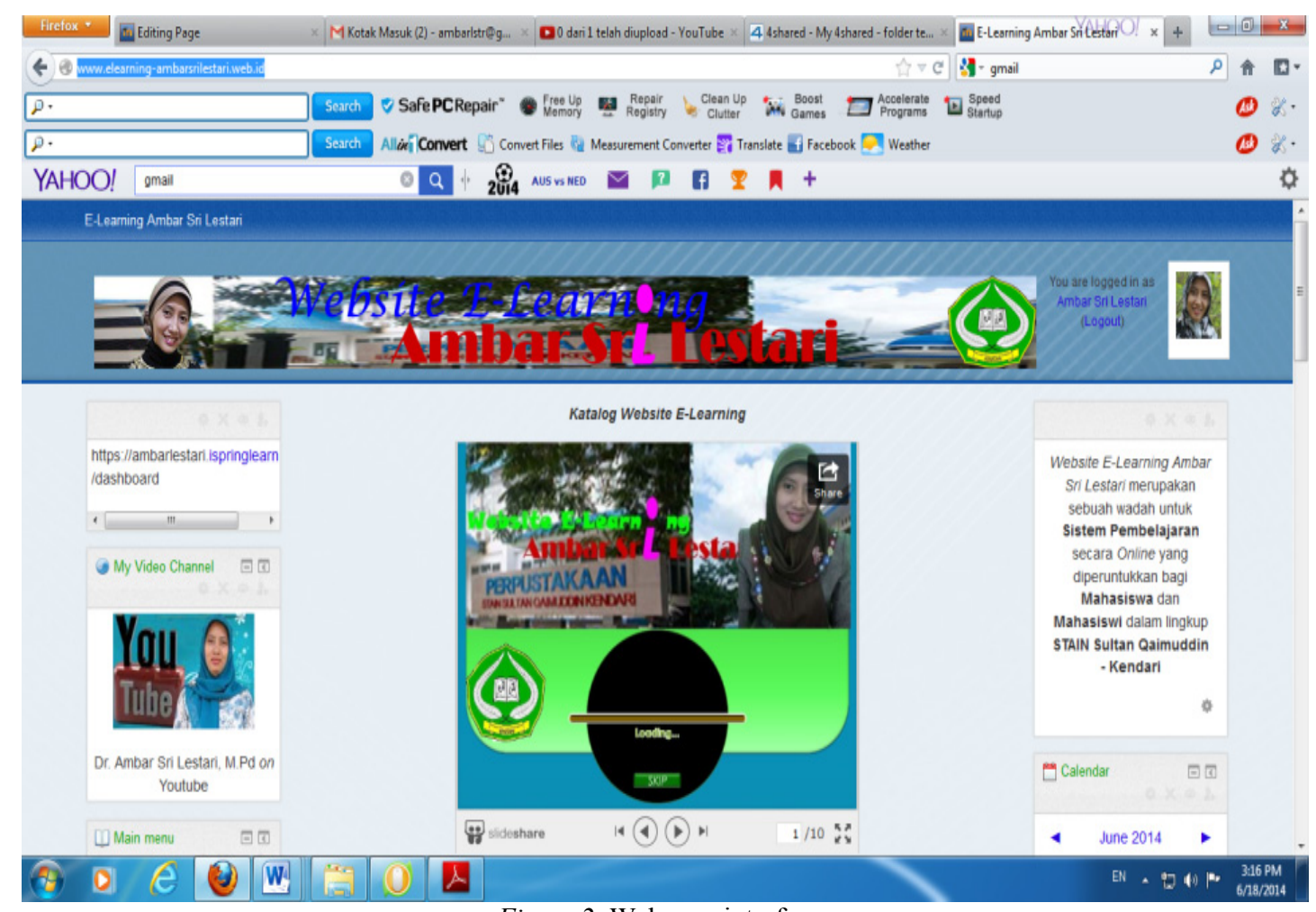

Figure 2. Web user interface.

2. On the right hand side, there is a Web course menu, select the course Instructional Media (see Figure 3).

3. In the menu display Instructional Media course, there are some lecture materials which have been uploaded to the Web for each meeting, knowledge sharing is done on a media blog that has been created by each of the students to post their writings (see Figure 4).

4. In addition to the blog, students can also use discussion forums, chat, and SlideShare (see Figure 5).

5. The process by which this process is part of knowledge management strategy will then become knowledge sharing. In performing knowledge sharing, new knowledge will be generated in the form of products and analysis of the problem, this can be done with discussions in the learning process. Then, last, technology, knowledge requires a storage media and technology is a tool/storage facility that is widely used in today's technological era. One of the data storages in the e-learning system which has been made is at 
http://www.elearning-ambarsrilestari.web.id/ on this Web, knowledge sharing can done on the portal forums, chat, and blogs (see Figures 6 and 7).



Figure 3. Class meeting.

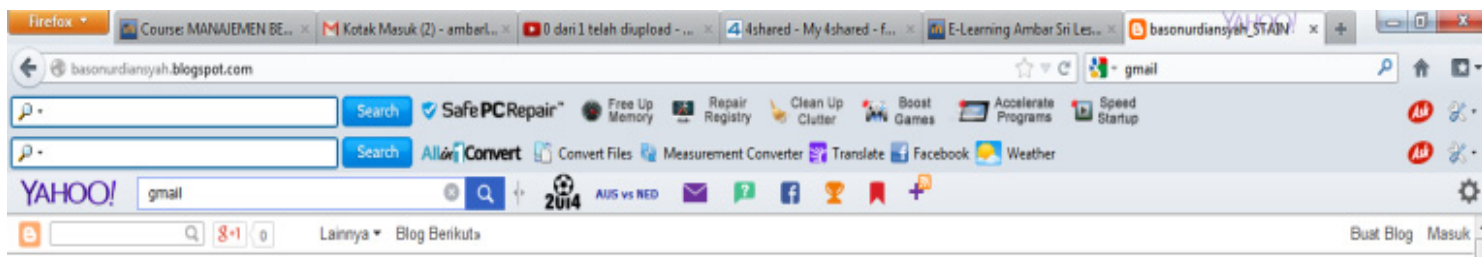

\section{basonurdiansyah_STAIN}



(4) D C (3) W.

Figure 4. Student blog. 


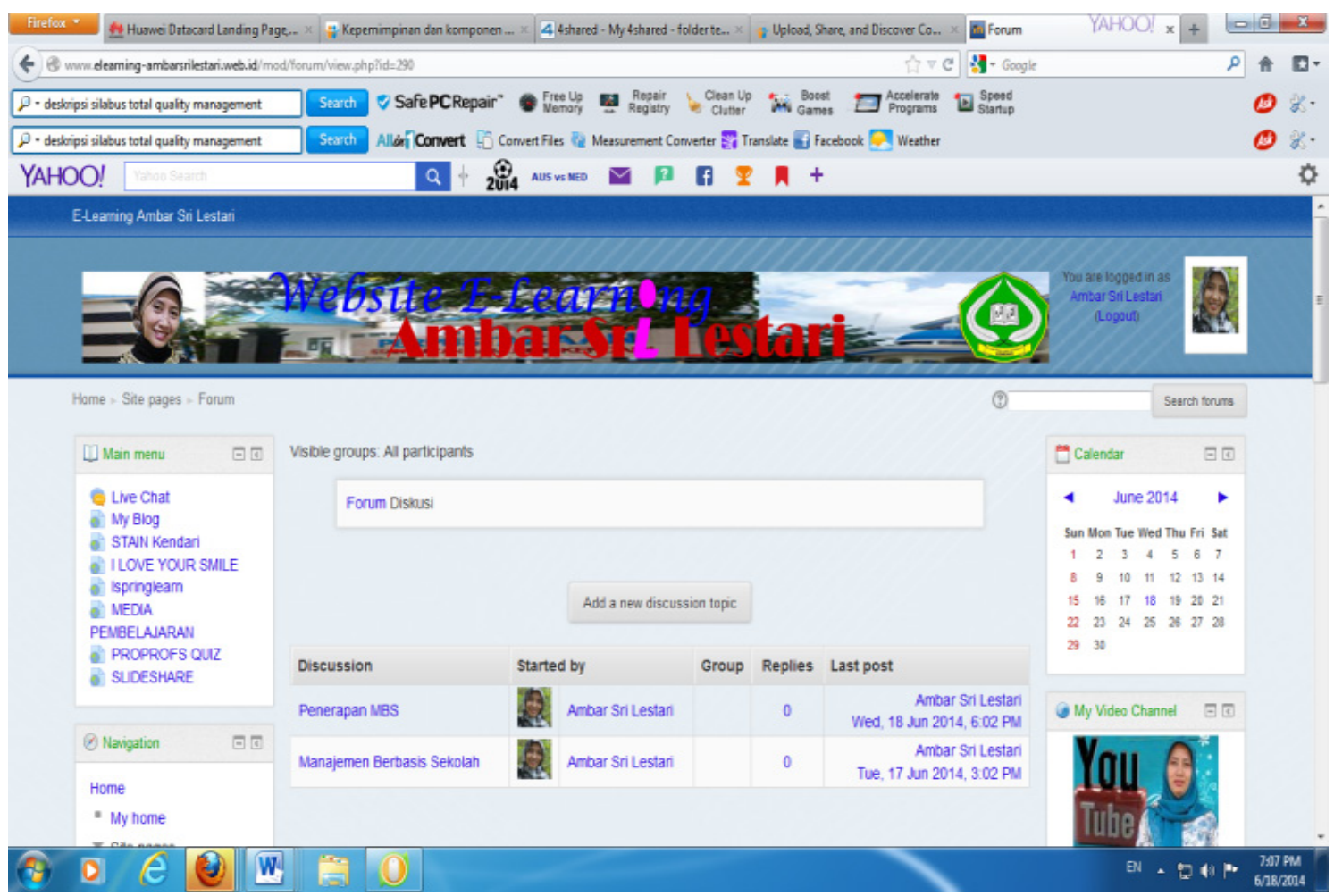

Figure 5. Student discussion forum.

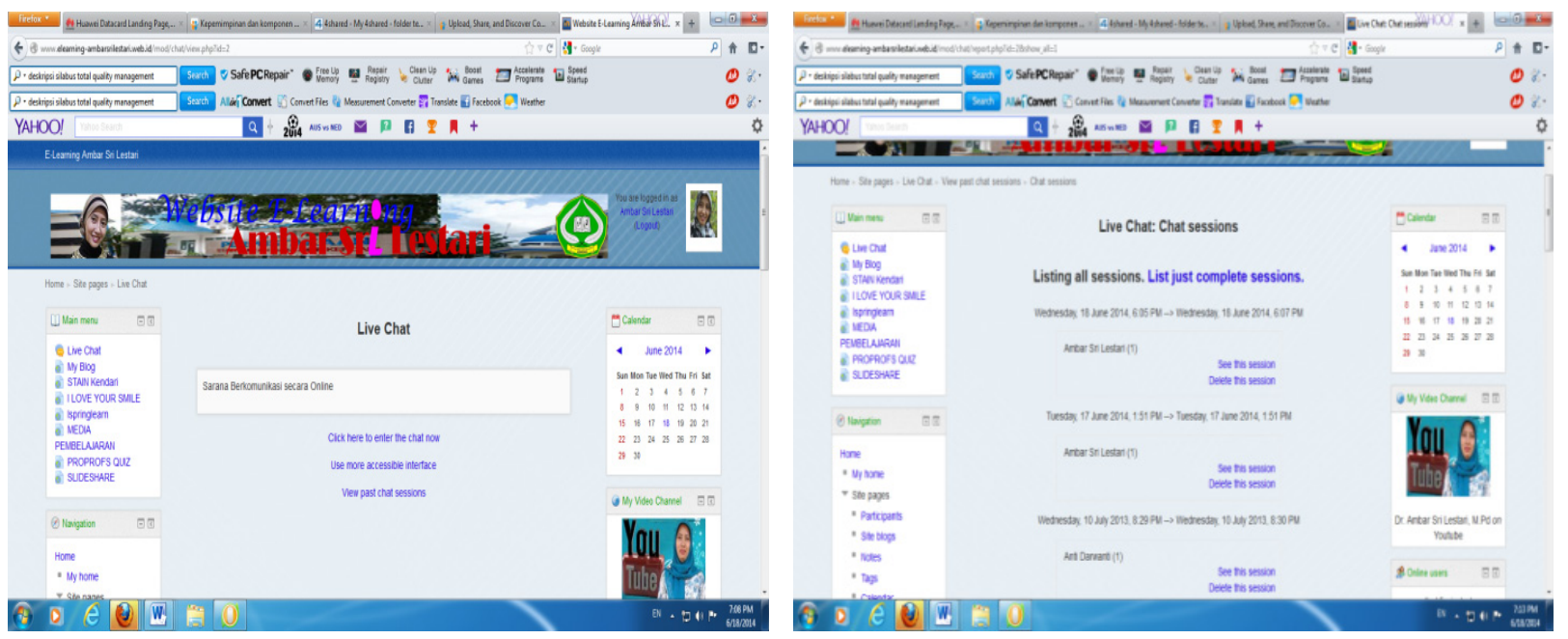

Figure 6. Live chatting of the students.

Constraints still exist now in IAIN Kendari: (a) low Internet access speed in classroom, which hampers the learning process with e-learning; and (b) most lecturers not taking advantage of e-learning in the learning process. With the functions contained in the e-learning, the stages of development of knowledge sharing are:

1. Knowledge: Knowledge is the result of a learning process that must be managed effectively to be presented explicitly (information, policies, and procedures), and implicit (knowledge, culture organization, habits, etc.). For each individual, knowledge can be ideas, opinions, talent, relationships, perspectives, and concepts, while together knowledge can be transformed in the form of technology, products, services, habits, facilities, and systems. E-Learning requires the knowledge of an individual or group to be managed, so that it 
can be used widely;

2. Database: One form of knowledge presentation is to use database. The database knowledge is the basic form of e-learning. By using the software, users will be able to do a search using the index and a guide with questions, through the command to do an assignment;

3. Software: The application used is learning management system to develop e-learning;

4. Human resources (qualifications and competences): Functionally, human resources associated with the use of e-learning. The groupings are: (a) regular users, i.e., users who utilize e-learning for the purpose of teaching or learning services. This requires a user group interface system that is the most efficient, the most interesting, and the most easy to use; and (b) business systems, i.e., those appointed to manage e-learning that is always up-to-date and in accordance with user needs. Business systems need to have the authority and the necessary technical competence to carry out their duties;

5. Financing for operations and maintenance of the system: To ensure the sustainability of the system, there is a need to analyze the operational and maintenance costs.
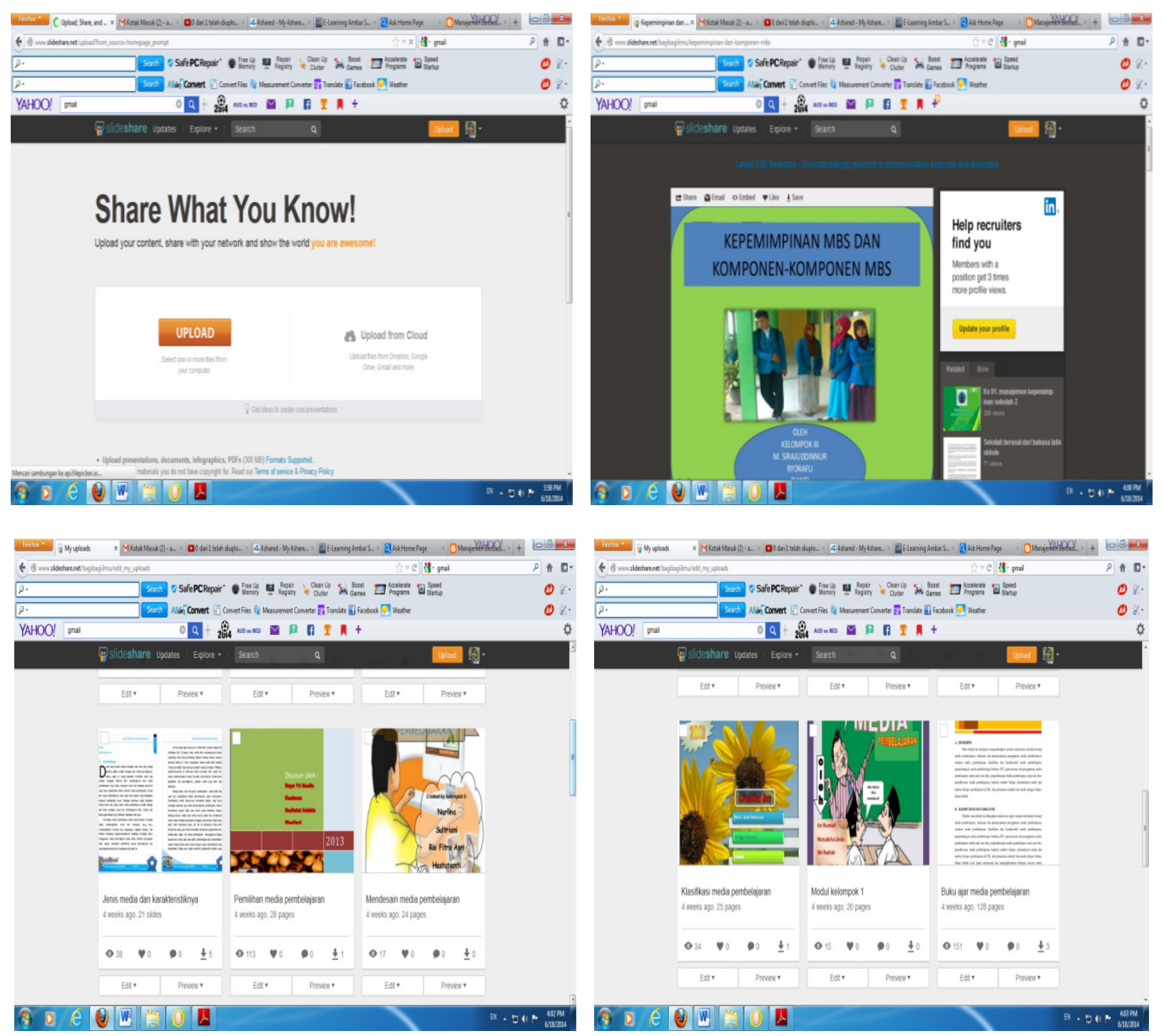

Figure 7. SlideShare resources. 


\section{Conclusion}

Overall, in the use of social media, the research results showed that $7.43 \%$ of the students use emails, $7.06 \%$ use Facebook, and 3.5\% use blogs. This implies that students often use emails as a means of learning activities. Through analysis using COLLES, overall, the students in conducting knowledge have a high degree of relevance of $3.98 \%$ on materials provided, which is higher than the others, i.e., $3.96 \%$ on items reflection, tutor support, peer support, and making sense, and $3.95 \%$ on interaction. In e-learning modalities, learning in IAIN Kendari included in the category of individualized self-paced elearning online. For example, the students conduct the learning process by accessing the source material (content resources) through the Internet and intranet as a source of materials, and online learning using the Website http://www.elearning-ambarsrilestari.we b.id, in which existing facilities, such as chat, discussion forums, and SlideShare can be used. Viewed from interaction of the students, the results of the questionnaire showed that the students still have a high level of comfort in synchronous learning compared with asynchronous learning via the Web. In the use of social media, Facebook utilization is quite high compared with other media, such as emails and blogs, so, the use of emails and blogs needs to be improved by using the Internet through e-learning as a process of knowledge sharing.

\section{References}

Bungin, B. (2003). Metode penelitian kualitatif (Qualitative research methods). Jakarta: Raja Grafindo Persada.

Clark, R. C., \& Mayer, R. E. (2008). E-learning and the science of instruction. San Francisco, C.A.: Pfeiffer.

Effendi, E., \& Zhuang, H. (2005). E-learning: Konsep dan aplikasi (E-learning: Concept and aplication). Yogyakarta: Andi Offet. Moleong, L. J. (2007). Metodologi penelitian kualitatif (Qualitative research methodology). Bandung: Remaja Rosdakarya Offset.

Naidu, S. (2006). E-learning: A guidebook of principles, procedures and practices (2nd revised edition). Commonwealth Educational Media Centre for Asia (CEMCA).

Nonaka, I., \& Takeuchi, H. (1995). The knowledge-creating company: How Japanese companies create the dynamics of innovation. Oxford, U.K.: Oxford University Press.

Rosenberg, M. J. (2001). E-learning: Strategies for delivering knowledge in the digital age. New York, N.Y.: McGraw-Hill Professional.

Soekartawi, S., Haryono, A., \& Librero, F. (2002). Greater learning opportunities through distance education: Experiences in Indonesia and the Philippines. Journal of Southeast Asian Education, 3(2).

Sudjana, N. (2001). Penelitian dan penilaian pendidikan (Research and assessment of education). Bandung: Sinar Baru.

Suharsimi, A. (2002). Prosedur penelitian: Suatu pendekatan praktek (Procedure research: A practice approach). Jakarta: Rhineka Cipta.

Sulistyo, B. (2006). Metode penelitian (Research methods). Jakarta: Wedatama Widya Sastra.

Taylor, P., \& Maor, D. (2000). Assessing the efficacy of online teaching with the Constructivist Online Learning Environment Survey. Retrieved from http://www.academia.edu/2835531/Assessing_the_efficacy_of_online_teaching_with_the_Construct ivist_Online_Learning_Environment_Survey 